\title{
Study on Subject Service Mode and the Significance of platform of University Libraries
}

\author{
Guishan Zhang ${ }^{1, a}$ \\ ${ }^{1}$ Jilin Agricultural University, Jilin, Changchun, 130118 \\ ${ }^{a}$ email
}

Keywords: Subject Service Mode, Discipline of Service Platform, Colleges Digital Library

\begin{abstract}
With the continuous expansion and transformation of the way of the Higher Education Service Discipline scale shift to discipline construction as the core, in order to improve the quality of the content-type development objectives, discipline level, subject contribution disciplines influence has become the core competitiveness of universities, for library service model put forward higher requirements, forcing the digital library to make a more rapid response, timely development and adjustment of development planning, coordination balanced development of technology, resources and services, and therefore the construction of University libraries subject service platform is very important.
\end{abstract}

\section{Introduction}

With the scale of China's higher education by the expansion of school-based extension development, shift to discipline construction as the core, in order to improve the quality of the content-type development objectives, discipline level, subject contribution disciplines influence has become the core competitiveness of universities, Library service model put forward higher requirements, forcing the library to make a more rapid response, the construction of University libraries Institutions of higher Learning service platform urgency more times. Digital Library is the library development to product information age revolution library services, innovative new service platform. University Libraries Service Discipline is the participation of subject librarians, library resources, subject-related information and Internet information reorganization to provide more accurate service information and documentation related to dynamic information is subject of the teaching and research . It is an innovative service model librarians use digital libraries, it has become one of the hot spots of University Library Information Service, University Libraries have introduced many domestic disciplinary service mechanism, and the establishment of a discipline on its Digital Library Portal navigation service.

\section{Subject Service Mode}

Existing manner disciplines and services includes navigation and discipline Subject Librarian System. To become a professional start, establish a resource library in the navigation disciplines from librarians. After the nineties more network resources navigation links are added to the subject in the past. With the development of Web2.0 technology, there have been a subject Navigation 2.0, that is, more abundant resource types, including pictures, video, navigation also diversified use of the RSS feeds, social bookmarking and so on.

Role and Function of Subject Librarians in the discipline in the service commitment is also changing. Development of the Subject Librarian of two stages, the first generation of librarians Subject librarians rely mainly on personal knowledge and ability to service users, the second subject librarian can use virtual technology to customer service. The future of the new generation of Subject Librarians are not only able to use their knowledge, skills and new technologies, but also embedded in the scientific process of users, providing real knowledge service 


\section{Digital Library and the Institutions of Higher Learning Service Platform}

"Digital Library" The term originated in the 1990s. Is a digital library environment, it collections, services, and people brought together to support the entire process of data, information and even knowledge, ranging from the creation, dissemination, use to save the whole process of the "Internet's broad reach and diverse service terminal Facilitating the use of network information numbers continue to increase, bringing new services to the information needs of the population, and rapidly changing information environment, the digital library technology, resources, services, and many other aspects put forward new demands, and force digital Library to make a more rapid response, timely development and adjustment of development planning, coordination balanced development of technology, resources and services information gateway generally focus on a related subject area, provided by the library staff selection and press subject resources organization. it is committed to information resources, tools and services specific subject areas integrated into a whole, to provide users with a convenient information retrieval and service entrance. in essence, the subject information portal containing different categories themes . pages and related links online library mainly characterized by a more human involvement, quality standards by selecting the resources to provide a rich description of resources; provide the basis for disciplinary architecture and resource type classification of browsing and searching the entrance; provide resources and application metadata indexing specification, resource sharing.

\section{Institutions of Higher Learning Service Platform Requirements}

College teachers and researchers some subjects, including research management personnel, limited time, space and their own abilities, not been able to use the library's resources, especially in the medical institutions of limited funding, limited purchasing capacity of database resources, so the library using its own resources (personnel, databases), fully collected disciplinary academic resources, and improve document delivery, which is the subject of the system integration services platform to build institutions of higher learning discipline provides a simple and convenient service is particularly important. Institutions of Higher Learning platform is a user-friendly service available on the same platform of information resources, access to information to help improve information literacy, and successfully conduct academic research and exchange of information service mode. Its constituent elements of space, resources and services, IC (integrated circuit) staff is to maintain these essential elements to ensure that the intermediate link play its function, which, subject areas related to the staff responsible for collecting resource information; discipline Hall University Libraries It is responsible for providing the finishing literature data subject; disciplinay internet service staff collect, compile and provide this frontier research trends, international trends and related disciplines resources. Disciplinay service platform integrates a variety of resources related disciplines, providing a one-stop information discovery and access path of discipline, adapted to the information needs discipline, better able to provide a unique and valuable service to users discipline is library core competitiveness of the main factors is deepening library services under the new situation, the need for service innovation, is to enhance the professional, personalized, knowledge-based information needs of library service capabilities, but also the sustainable development of the library premise.

\section{Features Institutions of Higher Learning Service Platform}

It supports the integrated use of various types of electronic library resources, databases, sub-categories by subject displayed.

Related Resources Department reorganization, this discipline provides special services.

Authority for a particular site collection, compile and provide this dynamic frontier research and international development trends, direct access to resources related disciplines.

Provide active push, online reference, subject SDI service, document delivery, questionnaire, 
updated regularly.

Automatic recording of the performance of subject librarians provide detailed analysis tools. In recent years, China has been expanding the size of school education-oriented extensional development, shift to discipline construction as the core, in order to improve the quality of the content-type development objectives, discipline level, subject contribution disciplines influence has become the core competitiveness Universities force. Subject to the terms of the construction of the strategic positioning of the University Library, organizational structure, personnel quality, resource development, service model and content put forward a full range of challenges and requirements.

\section{Significance of Universities Subject Service Platform}

Library disciplinay service platform, not only to deepen the service content in the new situation, the need for service innovation, but also enhance the professional, personalized, knowledge-based information service capabilities required library. Subject librarian service requirements subject to the user's in-depth research and teaching activities, helping them to discover and provide more specialized resources and information navigation, provide highly targeted information and services to users of the research work, the library service innovation embodied and personalized service, making the library's resources to interview more suited to user needs, library work more to give readers (teachers and students) recognition, enhanced communication and academic departments of the library. Subject Librarians targeted services according to the development needs and disciplines provided, is subject to provide value-added information services in the process. Subject librarians assist teachers in disciplines related topics counterparts literature search, the extensive collection of information resources based on the academic front, the hot, the representative works, new ideas, etc. to collect, collate, synthesize the like, so that teachers can discipline counterparts timely information on the latest research trends of a subject. Library implementation of research projects full service, support different document resources in accordance with the different stages of the project, can effectively improve the development of scientific research in various disciplines of enthusiasm and complete research tasks efficiently.

\section{Conclusion}

Corporate pursuit of profit, the pursuit of knowledge library added value of information resources, library social responsibility initiative positively, and that helps the library won a good social reputation, can also enhance the competitiveness of the library itself, the effective realization of Books Hall added value of the resources, which will effectively promote the sustainable development of the library, to create a more spacious living environment for the library for a wide range of human, financial social support for library development. Library to survive, develop and grow, not only to prevent unreasonable loss of resources, but also to increasing the rationality of resources, improve knowledge added value of information resources. If the library can consciously take the initiative to undertake extensive social responsibility, we can show the social value of libraries on a broader stage, to win more space for development, more social support.

\section{References}

[1] Wei Haiyan, Wei Junchao. Research libraries and services disciplines: from subject to subject librarian service platform [J]. Journal of Academic Libraries, 2013, (6): 73-79

[2] Xi Tao. Seats Review of Public Libraries Social Responsibility [J]. Library Journal, 2010 (7): 17-20.

[3] Wang Qun, Jiang Qi. University Library Subject Service [J]. Library Work and Research, 2007 (5): 86-88.

[4] Wei Dawei. Scientific planning and development of digital libraries: Exploration and Practice of the National Digital Library [J]. Library Theory and Practice, 2013 (4): 1-4, 10. 
[5] Zeng Lei, Zhang Jia, Yang Zongying. Digital libraries, Where: analysis of digital library definitions, structure and actual project [J]. Information Technology, 2000, 19 (1): 64-73. 